\title{
Current Situation of Oral Diseases Among Police Officers and Soldiers of Nam Dinh Provincial Public Security Department in Viet Nam, in 2019-2020: Examination, Diagnosis and Intervention with Some Biomedical Techniques
}

\section{Nguyen Huu Ban ${ }^{1 *}$, Dao Anh Son ${ }^{2}$, Vu Manh Tuan ${ }^{2}$ and Nguyen Thi Thuy Hanh ${ }^{2}$}

${ }^{1}$ PC11- Nam Dinh Provincial Public Security Department, Nam Dinh Province, Vietnam

${ }^{2}$ Ha Noi Medical University, Ha Noi city, Viet Nam

*Corresponding Author: Nguyen Huu Ban, PC11- Nam Dinh Provincial Public Security Department, Nam Dinh Province, Viet Nam.
Received: January 11, 2021

Published: January 31, 2021

(C) All rights are reserved by Nguyen Huu Ban., et al.

DOI: $10.31080 /$ ASDS.2020.05.1026

\begin{abstract}
Objectives: Describe the current state of oral disease and evaluate results of examination, diagnosis and some interventions with biomedical techniques among police officers and soldiers of Nam Dinh provincial public security department in Viet Nam, in 20192020.

Subjects and Research Methods: Description of cross section and vertical track intervention was performed with 843 officers and soldiers of Nam Dinh provincial public security department. The purpose of 3 regions was selected and each region was randomly selected 2 units. In each unit was selected, all police officers and soldiers of each unit were sampled. Information was collected by questionnaires, through direct questioning and clinical examination. Some biomedical techniques such as techniques of imaging diagnostics, techniques of oral imaging, digital photography, application of information technology, artificial intelligence to support examination, diagnosis and some oral disease interventions.

Results: Research results before intervention showed: The rate of 803 had oral diseases (95.2\%), of which there were 766 dental caries (90.8\%) and periodontal disease was 797 (94.5\%). The study only showed that the intervention efficiency index for Oral diseases was $39.4 \%$, the intervention efficiency index for tooth decay was $39.3 \%$, the intervention efficiency index for periodontal diseases was $57.7 \%$, the intervention efficiency index for gingivitis is $57.4 \%$, the intervention efficiency index for periodontitis was $38.5 \%$.

Conclusion: It is necessary to bring communication programs and instructions on oral hygiene, oral disease prevention measures supported by a number of biomedical techniques as well as periodic health checks for police officers and soldiers.
\end{abstract}

Keywords: Oral Disease; Biomedical Techniques; Police Officers and Soldiers

\section{Introduction}

Oral health refers to the health of the teeth, gums, and the entire oral-facial system that allows us to smile, speak, and chew. Some of the most common diseases that impact our oral health include cavities (tooth decay), periodontal disease (periodontal disease includes gingivitis and periodontitis) and oral cancer [1]. In the world, the rate of people suffering from oral diseases ac- counts for a high rate from 60 to nearly $100 \%$ of the population, of which tooth decay accounts for 50 to $97 \%$ of the population and periodontal disease accounts for 78 to $98 \%$ of the population [2-4]. Some studies in the country show that the rate of oral diseases from 50 to $100 \%$, of which tooth decay from 50 to $99 \%$ and periodontal diseases from 90 to $100 \%$ in adults [5]. Some studies on oral diseases in the police force around the world show that the rate of oral

Citation: Nguyen Huu Ban., et al. "Current Situation of Oral Diseases Among Police Officers and Soldiers of Nam Dinh Provincial Public Security Department in Viet Nam, in 2019-2020: Examination, Diagnosis and Intervention with Some Biomedical Techniques". Acta Scientific Dental Sciences 5.2 (2021):92-98. 
diseases among police officers is from 50 to $100 \%$, including the rate of tooth decay from $70 \%$ to $80 \%$ and the rate of periodontal diseases is from 75 to $100 \%$ [6-8]. A study done in the country on Oral disease among conscripts in the police showed that the rate of oral disease is from 80 to $90 \%$, of which the rate of tooth decay is $80 \%$, periodontal disease is $90 \%$ [9].

The People's Public Security Forces include the People's Security force, the People's Police force and the Commune Police force. In this study, using the phrase "Officer, soldier", is to include all: Officers, non-commissioned officers, soldiers, employees and labor contracts in the people's police (hereinafter referred to as O-S) [9].

Currently, with the development of biomedical science and technology such as techniques of imaging diagnostics, oral imaging techniques, digital photography, information technology, artificial intelligence applications have supported the examination, diagnosis and treatment of diseases in general medicine in general and in the dentistry in particular [10-12].

There have been many studies on oral diseases in different population groups in the community, but studies on oral examination, diagnosis and intervention by some biomedical techniques in the police still quite limited, hence the study "Current situation of oral diseases among police officers and soldiers of Nam Dinh provincial public security department in 2019-2020: examination, diagnosis and intervention with some biomedical techniques" is a necessary and highly practical issue. Research has two purposes:

- Describe the current situation of oral and dental diseases in police officers and soldiers, belonging to units of Nam Dinh provincial public security department in Viet Nam, in 20192020.

- Evaluate results of examination, diagnosis and some interventions with biomedical techniques.

Subjects and Research Methods

Research subjects

Police officers and soldiers of 6 units of the Nam Dinh Provincial Public security department have the official list of units, aged 1860 years old, voluntarily participating in the study.
Selection criteria

- $\quad$ All police officers and soldiers, both men and women of 6 units (aged 18-60) of Nam Dinh Provincial Public security department have an official list by unit.

- Voluntarily participate in research.

Exclusion criteria

- Including police officers and soldiers (O-S) on the list are selected but are ill, cannot participate or are receiving inpatient treatment for other diseases.

- Including police O-S on duty in other places who did not participate in oral examination during the research examination.

- Including police O-S on the selected list but studying at training institutions.

- Soldiers participating in the service (conscripts) in the People's Public Security Forces cannot leave their duties to participate during the time of conducting research (on duty, special duties).

Research methods

Time and place of the study

- $\quad$ Data collection time: From September 2019 to june 2020.

- $\quad$ Place of the study: At 06 units of the Nam Dinh provincial public security Department: Division PK02 (Mobile Police Force), Police of Nam Dinh City, Police of Vu Ban District, Police of Y Yen District, Police of Hai Hau District, Police of Giao Thuy District.

Research design: Description of cross section and vertical track intervention.

Sample size and sample selection

Sample size: Apply the sample size formula to estimate a ratio.

$$
n=D E * Z_{1-\alpha / 2}^{2} \frac{p(1-p)}{d^{2}}
$$

Inside:

$\mathrm{Z}_{1-\alpha / 2}=1.96$ (with reliability 95\%)

$\mathrm{d}=0.05$ expected error

$\mathrm{p}=0.8$ (the rate of tooth decay is $80 \%$ ) [9]. 
Design coefficient DE = 3 because in the study, we want to take all police officers and soldiers of 06 participating units.

Instead of the formula we have $\mathrm{n}=738$. In fact, researching on all 843 police officers and soldiers in 6 units of the Police Department of Nam Dinh province.

How to select a research sample: Selected purposefully according to 03 regions: The central region of industry and service of Nam Dinh city, the delta region: low-lying area and the delta region: coastal area. In each region, select randomly 2 units, in each selected unit, select all police officers and soldiers according to selection and exclusion criteria described above.

Information collection techniques

Cross-sectional descriptive studies: Clinical examination of oral diseases including cavities (tooth decay), periodontal disease (periodontal disease includes gingivitis and periodontitis) with biomedical techniques support such as dental mirror technique, halogen lamp, laser lamp, LED light, internal camera oral, digital photography, photographed by camera, smart phone, ipad, tablet, hand held dental x-ray film with sensor [11-13].

Intervention research: Intervention by communication, oral health education, oral hygiene, tartar removal, tooth polishing, filling cavities. Biomedical technology-assisted intervention process such as techniques of imaging diagnostics, oral imaging techniques, digital photography, information technology, artificial intelligence applications such as medical record management software, section HMU-Nextsol dental consultation and support software, Telehealth remote examination software, photo examination by phone and photo sending via social networks such as zalo, messenger, Viber, toothbrush with intellectual application artificially created such as Oral-B Genius X toothbrush and Kolibree's Ara toothbrush [14,15].

- Data collectors include 03 doctors (dentists), 02 physicians and 02 bachelors in nursing in dentistry, well trained before data collection.
- $\quad$ Research materials: Assistive biomedical technology such as dental mirror, internal camera oral, smartphone, digital camera, ipad, tablet, mobile film camera with sensor, smart brush with artificial intelligence application, instruction install software to support oral examination and counseling HMU-Nextsol, software for remote examination of Telehealth.

Data analysis and processing: Data was entered using Epidata 3.1 software and analyzed using Stata 14.2 software.

\section{Research ethics}

The research was conducted in accordance with the regulations on medical ethics in biomedical research. Approved by the Ethical Council for Research in Biomedical Medicine of Hanoi Medical University, according to the decision number: NCS31/DHYHNHDĐĐ of the Ethics Council, Hanoi University of Medicine, March 29, 2019.

\section{Results}

The study has 759 police officers and soldiers who are men, accounting for $90 \%$. Age, mainly from 18 to 30 years old (accounting for $67 \%$ ). The contents with a high rate such as education, college and university degrees (accounting for 68.6\%), belonging to the police block (accounting for 81.6\%). The contents at a low rate such as the age group from 45 to 60 (accounting for 3.7\%), the group with postgraduate degrees (accounting for 3.9\%), the group taking the leadership (accounting for 3.6\%).

In the study, 803 officers and soldiers (O-S) suffered from Oral diseases (accounting for 95.2\%), of which 766 0-S had tooth decay (accounting for 90.8\%), 797 0-S had periodontal diseases (accounting for 94.5\%), there are 791 O-S suffer from gingivitis $(93.8 \%)$ and $330-S$ had periodontitis (3.9\%).

After 06 months of intervention, 486 officers and soldiers (OS) suffered from oral disease (accounting for 57.7\%), 465 O-S suf- 
Current Situation of Oral Diseases Among Police Officers and Soldiers of Nam Dinh Provincial Public Security Department in Viet Nam, in 2019-2020: Examination, Diagnosis and Intervention with Some Biomedical Techniques

\begin{tabular}{|c|c|c|c|}
\hline \multicolumn{2}{|r|}{ Content } & $\mathbf{n}$ & $\%$ \\
\hline \multirow[t]{2}{*}{ Gender } & Male & 759 & 90.0 \\
\hline & Female & 84 & 10.0 \\
\hline \multirow[t]{3}{*}{ Age group } & $\geq 18$ and $\leq 34$ & 565 & 67.0 \\
\hline & $\geq 35$ and $\leq 44$ & 247 & 29.3 \\
\hline & $\geq 45$ and $\leq 60$ & 31 & 3.7 \\
\hline \multirow[t]{2}{*}{ Marital status } & Married & 604 & 71.7 \\
\hline & Single and unmarried & 239 & 28.3 \\
\hline \multirow[t]{3}{*}{ Educational level } & High school, professional intermediate & 65 & 7.7 \\
\hline & College/university & 578 & 88.4 \\
\hline & Postgraduate & 33 & 3.9 \\
\hline \multirow[t]{3}{*}{ Working unit of the block } & Politics, advisory, logistics & 74 & 8.8 \\
\hline & Police block & 688 & 81.6 \\
\hline & Security block & 81 & 9.6 \\
\hline \multirow[t]{3}{*}{ Working region } & The central region of industry and service of Nam Dinh city & 370 & 43.9 \\
\hline & The delta region: low-lying area & 256 & 30.4 \\
\hline & The delta region: coastal area & 217 & 25.7 \\
\hline \multirow[t]{2}{*}{ Nature of work } & Directly fighting crime & 588 & 69.8 \\
\hline & Not directly fighting crime & 255 & 30.3 \\
\hline \multirow[t]{3}{*}{ Job position } & Leader & 30 & 3.6 \\
\hline & Command & 226 & 26.8 \\
\hline & Officers and soldiers & 587 & 69.6 \\
\hline \multirow[t]{3}{*}{ Working time } & Administrative time & 224 & 26.6 \\
\hline & Working time in shifts & 52 & 6.2 \\
\hline & Working time is not fixed & 567 & 67.3 \\
\hline \multirow[t]{3}{*}{ Workplace } & Regularly have to go to work, on duty & 261 & 31.0 \\
\hline & Occasionally have to go to work, on duty & 246 & 29.2 \\
\hline & Working at the agency & 336 & 39.9 \\
\hline \multirow{3}{*}{$\begin{array}{l}\text { Perform unexpected tasks assigned by } \\
\text { superiors }\end{array}$} & Regularly accept unexpected missions & 265 & 31.4 \\
\hline & Occasionally receive unexpected missions & 505 & 59.9 \\
\hline & Not having to accept unexpected missions & 73 & 8.7 \\
\hline \multirow[t]{3}{*}{ Seniority of work } & $\leq 10$ years & 401 & 47.6 \\
\hline & $>10$ years, $\leq 20$ years & 343 & 40.7 \\
\hline & $>20$ years & 99 & 11.7 \\
\hline \multirow[t]{2}{*}{ Change job } & Usually change & 441 & 52.3 \\
\hline & Constant & 402 & 47.7 \\
\hline \multirow[t]{2}{*}{ Psychology, pressure of work } & Stress & 316 & 37.5 \\
\hline & without stress & 527 & 62.5 \\
\hline \multirow[t]{2}{*}{ Time for training and coaching } & Regular & 431 & 51.1 \\
\hline & Without regular & 412 & 48.9 \\
\hline
\end{tabular}

Table 1: General information about study subjects.

Citation: Nguyen Huu Ban., et al. "Current Situation of Oral Diseases Among Police Officers and Soldiers of Nam Dinh Provincial Public Security Department in Viet Nam, in 2019-2020: Examination, Diagnosis and Intervention with Some Biomedical Techniques". Acta Scientific Dental Sciences 5.2 (2021):92-98. 

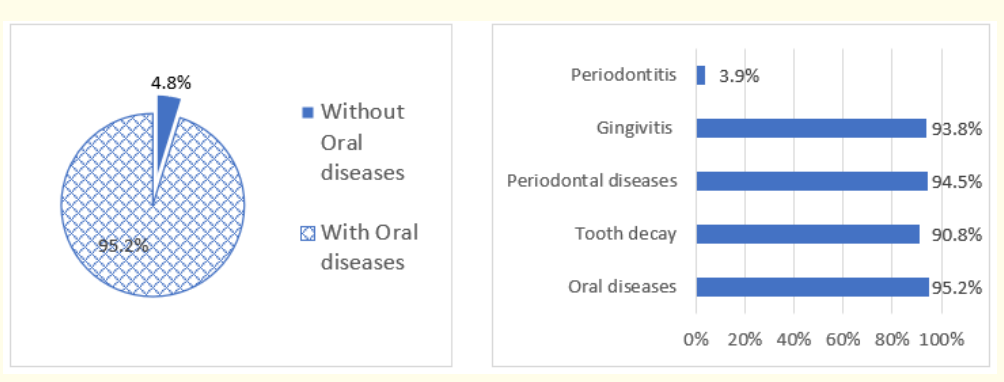

Figure 1: The rate of oral diseases of the police officers and soldiers of Nam Dinh province before the intervention.

\begin{tabular}{|l|c|c|c|c|}
\hline \multirow{2}{*}{ Type of disease } & \multicolumn{2}{|c|}{ With disease } & \multicolumn{2}{c|}{ Without disease } \\
\cline { 2 - 5 } & $\mathbf{n}$ & $\mathbf{\%}$ & $\mathbf{n}$ & $\mathbf{\%}$ \\
\hline Oral diseases & 486 & 57.7 & 357 & 42.3 \\
\hline Tooth decay & 465 & 55.1 & 521 & 44.9 \\
\hline Periodontal diseases & 337 & 40.0 & 506 & 60.0 \\
\hline Gingivitis & 337 & 40.0 & 506 & 60.0 \\
\hline Periodontitis & 20 & 2.4 & 823 & 97.6 \\
\hline
\end{tabular}

Table 2: Rate of oral disease among officers and soldiers of Nam Dinh province after 06 months of intervention.

fered from tooth decay (accounting for 55.1\%), 337 0-S suffered from periodontal diseases (accounting for 40.0\%), 337 O-S suf- fered from gingivitis (accounting for 40.0\%), 20 0-S suffered from periodontitis (accounting for $2.4 \%$ ).
The study only showed that the intervention efficiency index for Oral diseases was $39.4 \%$, the intervention efficiency index for tooth decay was $39.3 \%$, the intervention efficiency index for periodontal diseases was $57.7 \%$, the intervention efficiency index for gingivitis is $57.4 \%$, the intervention efficiency index for periodontitis was

\begin{tabular}{|c|c|c|c|c|c|c|}
\hline \multirow{3}{*}{ Type of disease } & \multicolumn{4}{|c|}{ With disease } & \multirow{3}{*}{$\begin{array}{c}\text { Intervention } \\
\text { efficiency index (\%) }\end{array}$} & \multirow{3}{*}{$\mathbf{p}$} \\
\hline & \multicolumn{2}{|c|}{ Before intervention } & \multicolumn{2}{|c|}{ After intervention } & & \\
\hline & $\mathbf{n}$ & $\%$ & $\mathbf{n}$ & $\%$ & & \\
\hline Oral diseases & 803 & 95.2 & 486 & 57.7 & 39.4 & $<0.01$ \\
\hline Tooth decay & 766 & 90.8 & 465 & 55.1 & 39.3 & $<0.01$ \\
\hline Periodontal diseases & 797 & 94.5 & 337 & 40.0 & 57.7 & $<0.01$ \\
\hline Gingivitis & 791 & 93.8 & 337 & 40.0 & 57.4 & $<0.01$ \\
\hline Periodontitis & 33 & 3.9 & 20 & 2.4 & 38.5 & $<0.01$ \\
\hline
\end{tabular}

Table 3: Effective interventions for oral diseases after 06 months for police officers and soldiers in Nam Dinh province. 
$38.5 \%$ and these intervention efficiency indicators are statistically significant with $\mathrm{p}<0.01$.

\section{Discussion}

The research results showed that the study had 843 officers and soldiers participating in the study, including 759 men, accounting for $90 \%$. The main age group is from 18 to 30 years old (accounting for 67\%); 803 officers and soldiers suffered from Oral diseases (accounting for 95.2\%), 766 officers and soldiers suffered from tooth decay (accounting for 90.8\%) and 797 officers and soldiers suffered from periodontal diseases (accounting for 94.5\%). This rate is somewhat similar to the study of 475 police officers and soldiers in Mathura city, Uttar Pradesh state of India, in which there were 473 men (accounting for 99.6\%) and 2 women (accounting for $0.4 \%$ ), $62.3 \%$ of the age under 35 years old, the rate of oral diseases is $80.4 \%$ [16]. Another study was done with 172 police officers and soldiers participating in the study in Virajpet, in the southern part of India, there were 154 men (accounting for 89.5\%) and 18 women (accounting for 10.5\%), the rate of dental caries is 78\% [17]. Another study was done with 925 Peruvian police officers and soldiers, there were 797 men ( accounting for 86.2\%) and 128 women (accounting for 13.8\%), the rate of dental caries is $73.4 \%$ [8]. A study was done in the country, conducted on 110 soldiers participating in the police service of Nam Dinh Provincial Police, had 99 soldiers, accounting for $90 \%$ of oral diseases [9]. However, there is a difference in the prevalence of oral diseases in our study with some foreign studies because our study subjects are Vietnamese, the time of the study, the application of the method

\begin{tabular}{|c|c|c|}
\hline Content & Common technique & Biomedical techniques \\
\hline $\begin{array}{l}\text { Examination } \\
\text { process }\end{array}$ & $\begin{array}{c}\text { More time (usually } 10 \text { minutes/01 patient) [9]. } \\
\text { The operation is more difficult [9]. } \\
\text { Some cases of caries, diseases around the teeth could } \\
\text { not be detected by conventional methods [9]. }\end{array}$ & $\begin{array}{l}\text { Shorter time (usually } 05 \text { minutes } / 01 \text { patient } \\
\text { Easier operation } \\
\text { Detecting fields of dental caries and periodontal dis- } \\
\text { eases that cannot be detected by conventional methods }\end{array}$ \\
\hline Diagnose & For lower results. Rate of oral disease is $80 \%$ [9]. & $\begin{array}{l}\text { For more accurate results. The rate of oral diseases is } \\
\qquad 95.2 \%\end{array}$ \\
\hline
\end{tabular}

Table 4: Comparison of examination, diagnosis and interventions of oral diseases using conventional techniques with biomedical technology support.

and the diagnostic standards of different oral diseases.

Comment: The process of oral examination, diagnosis and intervention supported by a number of biomedical techniques will save time for the examination, examination and diagnosis more accurately, oral disease intervention will be more effective.

\section{Conclusion}

Descriptive cross-sectional study, conducted on 843 police officers and soldiers of Nam Dinh Provincial Police, showed that the rate of oral disease was very high (accounting for 95.2\%), 766 officers and soldiers had dental cavities (accounting for 90.8\%) and 797 soldiers and soldiers had periodontal diseases (accounting for $94.5 \%)$.
The process of oral examination, diagnosis and intervention supported by a number of biomedical techniques will save time for the examination, diagnosis more accurately and oral disease intervention will be more effective.

\section{Conflict of Interest}

All the authors declare that they do not compete, conflict of interest.

\section{Acknowledgment}

To complete this research, our research team would like to express our sincere gratitude to:

- $\quad$ Rector Board, Postgraduate Training Office, Institute of Medicine and Public Health Training of Hanoi Medical University. 
- $\quad$ Police of Nam Dinh province and Department of Health of Nam Dinh province.

\section{Bibliography}

1. WHO. "Oral health". (2020).

2. WHO. WHO | "What is the burden of oral disease?" (2020).

3. Blackwell DL., et al. "Regional Variation in Private Dental Coverage and Care Among Dentate Adults Aged 18-64 in the United States, 2014-2017". NCHS Data Brief 336 (2019): 1-8.

4. Nazir M., et al. "Global Prevalence of Periodontal Disease and Lack of Its Surveillance". The Scientific World Journal 2020 (2020).

5. Tran Duc Thanh. Public Dentistry. Medical Publishing House, Ho Chi Minh City branch (2012).

6. Bhardwaj V., et al. "Assessment of oral health status and treatment needs of police personnel in Shimla city, Himachal Pradesh: A cross-sectional study". International Journal of Health and Allied Sciences 1.1 (2012): 20.

7. Nagesh A., et al. "Impact of caries prevalence on oral health-related quality of life among police personnel in Virajpet, South India". Journal of International Society of Preventive and Community Dentistry 4.3 (2014): 188.

8. Moreno-Quispe LA., et al. "Dental caries in the peruvian police population". Journal of Clinical and Experimental Dentistry 10.2 (2018): e134-e138.

9. Nguyen Huu Ban. "Current situation of oral diseases and factors related to oral disease among soldiers serving for a limited period of time in the people's police at Nam Dinh Provincial Police, 2015 - 2016". Journal of Vietnam Medicine 452 (2017): 129-134.

10. Qi S., et al. "The development of dental informatics and dental information technology in China: A systematic study". Journal of Dental Science 10.2 (2015): 176-184.

11. Saini R. "Information Technology in Dentistry". Dentistry 6.8 (2016).
12. Chen Y-W., et al. "Artificial intelligence in dentistry: current applications and future perspectives". Quintessence International 51.3 (2020): 248-257.

13. Desai V and Bumb D. “Digital Dental Photography: A Contemporary Revolution". International Journal of Clinical Pediatric Dentistry 6.3 (2013): 193-196.

14. Oral B. "A revolutionary toothbrush with artificial intelligence". British Dental Journal 227.1 (2019): 62-62.

15. Kolibree's Ara. "Features of the new Ara Smart Toothbrush with artificial intelligence" (2020).

16. Bhalla M., et al. "Oral Health Status and Treatment Needs of Police Personnel in Mathura City". Journal of International Oral Health 7.9 (2015): 51-53.

17. Zaitsu T., et al. "Relationships between occupational and behavioral parameters and oral health status". Indian Health 55.4 (2017): 381-390.

18. Nguyen Anh Son., et al. "The Effect of Oral Health Care Reduces The Rate of Dental Cavities and Gingivitis of Secondary School Students in Binh Xuyen District, Vinh Phuc Province, in 2016". Journal of Preventive Medicine and Public Health 28.12 (2018): 107-115.

\section{Assets from publication with us}

- Prompt Acknowledgement after receiving the article

- Thorough Double blinded peer review

- Rapid Publication

- Issue of Publication Certificate

- High visibility of your Published work

Website: www.actascientific.com/

Submit Article: www.actascientific.com/submission.php Email us: editor@actascientific.com

Contact us: +919182824667 